\title{
TO COMPARE THE EFFICACY OF DIFFERENT PROSTAGLANDINS AS MONOTHERAPY IN POAG
}

\author{
Uttam Prakash Deepankar'1, Bahubali Jain ${ }^{2}$
}

${ }^{1}$ Associate Professor, Department of Ophthalmology, NSCB Medical College, Jabalpur.

${ }^{2}$ Assistant Professor, Department of Ophthalmology, NSCB Medical College, Jabalpur.

\section{ABSTRACT}

\section{BACKGROUND}

Glaucoma a chronic, progressive optic neuropathy, is an important cause of blindness. Prostaglandin analogues are new class of very potent IOP lowering agent with a unique mechanism of action. Four agents are in the category of prostaglandins, also called hypotensive lipids. These are Latanoprost, Unoprostone, Travoprost and Bimatoprost.

\section{METHOD}

This prospective randomized study was conducted on 60 newly diagnosed cases of primary open angle glaucoma attending Glaucoma Clinic of the Department of Ophthalmology N.S.C.B. Medical College Jabalpur between December 2014 and November 2015 , wherein the cases are divided into 3 groups (20 eyes each) to compare efficacy of all the three prostaglandins. The IOP lowering efficacy of drugs was assessed in different timeframes from 24 hours to four weeks. However, the final IOP lowering by drugs was assessed at the end of 4 weeks.

\section{RESULT}

The mean IOP reduction by travoprost, latanoprost and bimatoprost at the end of 4 weeks was found to be $31.83 \%, 31.40 \%$ and $31.77 \%$.

\section{CONCLUSION}

Latanoprost, bimatoprost and travoprost were comparable in their ability to reduce IOP in OAG and OH patients and typically reduce IOP by $20 \%-35 \%$.

\section{KEYWORDS}

POAG, PGs, IOP, OH.

HOW TO CITE THIS ARTICLE: Deepankar UP, Jain B. To compare the efficacy of different prostaglandins as monotherapy in POAG. J. Evolution Med. Dent. Sci. 2016;5(66):4713-4715, DOI: 10.14260/jemds/2016/1074

\section{INTRODUCTION}

Glaucoma, a chronic, progressive optic neuropathy is an important cause of blindness. It is estimated that $5.8 \%$ of the blindness in India is caused by glaucoma. It is estimated that there will be $79.6 \%$ million cases of glaucoma worldwide by 2020. Of these, $74 \%$ will have open angle glaucoma.

Early detection and treatment can slow or even halt the progression of the disease. Research over two decades has identified IOP as the only risk factor, which we can currently modulate to halt the progression of glaucoma. Hence, presently our therapeutic tools focus on lowering the IOP to a level, which prevents functional visual loss for the rest of the patient's life.

Prostaglandin analogues are new class of very potent IOP lowering agent with a unique mechanism of action. Four agents are in the category of prostaglandins, also called hypotensive lipids. These are Latanoprost (Approved in 1996) [Goldberg I, Cunha-Vaz J, Jakobsen JE, et al].1 Unoprostone (Approved in 2000) [Fellman RL, Sullivan EK, Ratliff M, et al].2 travoprost (Approved in 2001) [Alm A, Stjernschantz J]. ${ }^{3}$ and Bimatoprost (Approved in 2001 Mario VA, Margarita LatLuna). ${ }^{4}$

Financial or Other, Competing Interest: None.

Submission 06-06-2016, Peer Review 02-07-2016,

Acceptance 07-07-2016, Published 17-08-2016.

Corresponding Author:

Dr. Bahubali Jain,

C 409 Vatsala Paradise,

Shivnagar Jabalpur-482002,

Madhya Pradesh.

E-mail: drbahu@gmail.com

DOI: $10.14260 /$ jemds/2016/1074
According to Data on the prostaglandin analogues from the U.S. Food and Drug Administration labelled package insert, 2002.5

\begin{tabular}{|c|c|c|}
\hline Drug & $\begin{array}{c}\text { Baseline } \\
\text { IOP }\end{array}$ & $\begin{array}{c}\text { IOP Reduction } \\
\text { from Baseline }\end{array}$ \\
\hline $\begin{array}{c}\text { Travoprost } \\
0.04 \%\end{array}$ & $25-27$ & $7-8$ \\
\hline $\begin{array}{c}\text { Latanoprost } \\
0.005 \%\end{array}$ & $25-25$ & $6-8$ \\
\hline $\begin{array}{c}\text { Bimatoprost } \\
0.03 \%\end{array}$ & 26 & $7-8$ \\
\hline
\end{tabular}

\section{MATERIALS AND METHODS}

This prospective randomized study was conducted on 60 newly diagnosed cases of primary open angle glaucoma attending Glaucoma Clinic of the Department of Ophthalmology N.S.C.B. Medical College Jabalpur between December 2014 to November 2015, wherein the cases are divided into 3 groups ( 20 eyes each) to compare efficacy of all the three prostaglandin.

- Group A: Travoprost $0.04 \%$

- Group B: Latanoprost $0.005 \%$

- Group C: Bimatoprost $0.03 \%$

All the cases were recorded in a pre-designed proforma. It included age, sex, visual acuity, pupillary reaction, flashlight test, Van Herick test, slit lamp biomicroscopy, GAT, gonioscopy and fundus examination. 


\section{Exclusion Criteria}

1. Patients who are non-compliant to medication.

2. Advanced cataract in which field and Optic Disc evaluation could not be done.

3. Patients requiring combination drug therapy.
4. All patients with secondary glaucoma such as any ocular infection, e.g. keratitis, uveitis, choroiditis, H/O ocular trauma, lens induced glaucoma, ocular malignancies, etc.

5. Patients having systemic diseases, which are known to be aggravated by anti-glaucoma medication.

\section{OBSERVATIONS}

IOP Lowering Efficacy of different Prostaglandin

\begin{tabular}{|c|c|c|c|c|c|c|c|c|c|}
\hline \multirow{3}{*}{$\begin{array}{l}\text { Time } \\
\text { Frame }\end{array}$} & \multicolumn{3}{|c|}{ Travoprost } & \multicolumn{3}{|c|}{ Latanoprost } & \multicolumn{3}{|c|}{ Bimatoprost } \\
\hline & \multirow{2}{*}{$\begin{array}{l}\text { Mean } \\
\text { IOP }\end{array}$} & \multicolumn{2}{|c|}{$\begin{array}{c}\text { IOP } \\
\text { From Baseline }\end{array}$} & \multirow{2}{*}{$\begin{array}{c}\text { Mean } \\
\text { IOP }\end{array}$} & \multicolumn{2}{|c|}{$\begin{array}{c}\text { IOP } \\
\text { From Baseline }\end{array}$} & \multirow{2}{*}{$\begin{array}{c}\text { Mean } \\
\text { IOP }\end{array}$} & \multicolumn{2}{|c|}{$\begin{array}{c}\text { IOP } \\
\text { From Baseline }\end{array}$} \\
\hline & & MMHG & $\%$ & & MMHG & $\%$ & & MMHG & $\%$ \\
\hline Baseline IOP & 25.57 & & & 25.03 & & & 24.77 & & \\
\hline Day 1 & 21.70 & 3.87 & 15.13 & 21.43 & 3.6 & 14.38 & 20.63 & 4.14 & 16.71 \\
\hline 2 & 20.77 & 4.8 & 18.77 & 21.30 & 3.73 & 14.90 & 20.50 & 4.27 & 17.23 \\
\hline 3 & 20.37 & 5.2 & 20.33 & 20.77 & 4.26 & 17.01 & 20.23 & 4.54 & 18.32 \\
\hline 4 & 19.97 & 5.6 & 21.90 & 20.37 & 4.66 & 18.61 & 20.10 & 4.67 & 18.85 \\
\hline 5 & 19.17 & 6.4 & 25.02 & 19.97 & 5.06 & 20.21 & 19.30 & 5.47 & 22.08 \\
\hline 6 & 18.63 & 6.94 & 27.14 & 19.70 & 5.33 & 21.29 & 19.03 & 5.74 & 23.17 \\
\hline Week 1 & 18.37 & 7.2 & 28.15 & 19.17 & 5.86 & 23.41 & 18.50 & 6.27 & 25.31 \\
\hline 2 & 17.97 & 7.6 & 29.72 & 17.87 & 7.16 & 28.60 & 17.83 & 6.94 & 28.01 \\
\hline 3 & 17.70 & 7.87 & 30.77 & 17.30 & 7.73 & 30.88 & 17.70 & 7.07 & 28.54 \\
\hline 4 & 17.43 & 8.14 & 31.83 & 17.17 & 7.86 & 31.40 & 16.90 & 7.87 & 31.77 \\
\hline
\end{tabular}

\section{DISCUSSION}

1. An average lowering of $31.83 \%$ was observed from baseline after four weeks of Travoprost therapy, which was statistically significant. However, significant lowering of $15.13 \%$ was also observed even after 24 hours of instillation.

2. An overall lowering of $31.40 \%$ was observed from baseline after four weeks of Latanoprost therapy, which was statistically significant. However, significant lowering of $14.38 \%$ was also observed even after 24 hours after instillation.

3. An overall lowering of $31.77 \%$ was observed from baseline after four weeks of Bimatoprost therapy, which was statistically significant. However, significant lowering of $16.71 \%$ was also observed even after 24 hours after instillation.

The IOP lowering efficacy of drugs was assessed in different time frames from 24 hours to 4 weeks. However, the final IOP lowering by drugs was assessed at the end of 4 weeks.

With regards to the efficacy of Prostaglandins as monotherapy, there are conflicting reports in the literature. However, all the reports uniformly mention that the prostaglandins have highest pressure lowering efficacy. The range of pressure lowering varies between 25-35\%. [Brandt JD, VanDenburgh AM, Chen K, et al].6

The IOP lowering efficacy of the drugs has been found to vary in different studies. This variation may be because of difference in the inclusion criteria such as inclusion of normal tension glaucoma cases, different grades of severity of open angle glaucoma, different types of glaucoma, difference in age and refractive status and method of recording IOP.

However, if the standard method of recording the pressure and inclusion of all subtypes of OPAG in all age groups all grades of severity are considered, then the overall efficacy of drugs that we observed are in accordance with other studies.

Reports to compare the IOP lowering efficacy in different timeframes are very few. We recorded IOP on a daily basis for
1 week and on a weekly basis for 4 weeks. Larsson LI. ${ }^{7}$ found significant IOP lowering at end of 24 hours with use of latanoprost. It is our observation that most of the drugs produce significant IOP lowering even after 24 hours of initiation of therapy, which continues till four weeks. This finding can be of clinical importance in control of intraocular pressure immediately in situations such as IOP spikes following laser treatments or acute rise in intraocular pressure due to other causes of glaucoma.

Latanoprost, bimatoprost and travoprost were comparable in their ability to reduce IOP in OAG and $\mathrm{OH}$ patients. [Higginbotham EJ, Schuman JS, Goldberg I, et al].8 Latanoprost exhibited greater ocular tolerability. [Parrish RK et al, 2003].9

Bimatoprost has been compared with latanoprost and showed a comparable IOP-lowering effect. [DuBiner H, Cooke D (2001).10; Gandolfi et al (2001).11 Noecker RS et al (2003).12]

Prostaglandin analogues are generally more effective in terms of lowered intra-ocular pressure [June Chen, David F Woodward et al].13

Latanoprost, bimatoprost and travoprost have been shown to be equal in lowering pressure in patients with OAG or ocular hypertension and typically reduce IOP by $20 \%-35 \%$ [SM Whticup et al, 2003].14

\section{SUMMARY AND CONCLUSION}

The prospective study entitled "A comparative study of efficacy of different prostaglandin as monotherapy in POAG shows following observations:

1. The mean IOP reduction by travoprost, latanoprost and bimatoprost at the end of 4 weeks was found to be $31.83 \%, 31.40 \%$ and $31.77 \%$.

2. All the three prostaglandins were found to have nearly equal efficacy.

3. Latanoprost therapy has lowest incidence of hyperaemia among the prostaglandins group. 
4. The dry eye, foreign body sensations and pain in the eye were infrequent side effects of prostaglandins therapy.

5. More studies are needed to assess the IOP lowering efficacy of various antiglaucoma medications in different timeframes. From such studies more detailed information may be obtained regarding the clinical use of drugs.

6. The variation in the pressure lowering efficacy of any drug needed to be studied further. Factors such as degree and type of glaucomatous damage, age of the patient, race of the patient, degree of pigmentation and initial height of intraocular pressure may determine the pressure lowering efficacy of the drug.

\section{REFERENCES}

1. Goldberg I, Cunha-Vaz J, Jakobsen JE, et al. Comparison of topical travoprost eye drops given once daily and timolol $0.5 \%$ given twice daily in patients with open-angle glaucoma or ocular hypertension. J Glaucoma 2001;10(5):414-22.

2. Fellman RL, Sullivan EK, Ratliff M, et al. Comparison of travoprost $0.0015 \%$ and $0.004 \%$ with timolol $0.5 \%$ in patients with elevated intraocular pressure: a 6-month, masked multicenter trial. Ophthalmology 2002;109(5):998-1008.

3. Alm A, Stjernschantz J. Effects on intraocular pressure and side effects of $0.005 \%$ latanoprost applied once daily, evening or morning a comparison with timolol. Scandinavian Latanoprost Study Group Ophthalmology 1995;102(12):1743-52.

4. Mario VA, Lat-Luna M. The effect of Latanoprost vs timolol on intra ocular pressure I patients with glaucoma and ocular hypertension. Asian J Ophthalmol 1999;1(3):3-7.

5. Einarson TR, Kulin NA, Tingey D, et al. Meta-analysis of the effect of latanoprost and brimonidine on intraocular pressure in the treatment of glaucoma. Clin Ther 2000;22(12):1502-15.
6. Brandt JD, Denburgh VAM, Chen K, et al. Comparison of once- or twice-daily bimatoprost with twice-daily timolol in patients with elevated IOP: a 3-month clinical trial. Ophthalmology 2001;108(6):1023-31.

7. Larsson LI. Intraocular pressure over 24 hours after singledose administration of latanoprost $0.005 \%$ in healthy volunteers a randomized, double-masked, placebo controlled, cross-over single center study. Acto Ophthalmol Scand 2001;79(6):567-71.

8. Higginbotham EJ, Schuman JS, Goldberg I, et al. One-year, randomized study comparing bimatoprost and timolol in glaucoma and ocular hypertension. Arch Ophthalmol 2002;120(10):1286-93.

9. Parrish RK, Palmberg P, Sheu WP. A comparison of latanoprost, bimatoprost, and travoprost in patient with elevated intraocular pressure: a 12-week, randomized, masked-evaluator multicenter study. Am J Ophthalmol 2003;135(5):688-703.

10. DuBiner H, Cooke D, Dirks M, et al. Efficacy and safety of bimatoprost in patients with elevated intraocular pressure: a 30-day comparison with latanoprost. Surv Ophthalmol 2001;45(4):S353-60.

11. Gandolfi S, Simmons ST, Sturm R, et al. Bimatoprost study group. Three-month comparison of bimatoprost and latanoprost in patients with glaucoma and ocular hypertension. Adv Ther 2001;18(3):110-21.

12. Noecker RS, Dirks MS, Choplin NT, et al. A six-month randomized clinical trial comparing the intraocular pressure-lowering efficacy of bimatoprost and latanoprost in patients with ocular hypertension or glaucoma. Am J Ophthalmol 2003;135(1):55-63.

13. Chen J, Woodward DF. Fixed-combination and emerging glaucoma therapies. Expert Opinion on Emerging Drugs 2007;12(2):313-27.

14. Whitcup SM, Cantor LB, Denburgh AM, et al. A randomized, double masked, multicenter clinical trial comparing bimatoprost and timolol for the treatment of glaucoma and ocular hypertension. Br J Ophthalmol 2003;87(1):57-62. 